\title{
On-load Back-EMF Optimization Based on the Back-EMF MST Method and Parametric Optimization
}

\author{
Luiz Henrique Reis de Jesus (D), Geyverson Teixeira de Paula (D), Leonardo da Cunha Brito (i) \\ School of Electrical, Mechanical and Computer Engineering, Federal University of Goiás \\ Goiânia, GO 74605-220, Brazil \\ luizhenriqueengineer@gmail.com ${ }^{1}$,geyverson@gmail.com ${ }^{2}$, brito.lc@gmail.com ${ }^{3}$
}

\begin{abstract}
This paper proposes an optimal design for a surface mounted permanent magnet synchronous machine (SM-PMSM) based on parametric optimization process to reduce the on-load Back-EMF distortions caused by an increase in the electromagnetic load and in the saturation. Unlike conventional methods described in the literature, the optimization approach proposed here accounts for the saturation effects, air gap flux density distribution and the evaluation of the on-load Back-EMF by means of finite element analysis, allied to the most recent on-load Back-EMF evaluation method, known as the Back-EMF MST (Maxwell stress tensor) method. Furthermore, the optimization process is performed considering either the machine's physical symmetry (based on pole numbers) and its nonevident symmetry (based on saturation effects and on the relevance of each tooth in the Back-EMF waveform), which is identified using the Back-EMF MST method. The proposed optimization process also analyzes different sets of variables based on symmetric and asymmetric tooth dimensions. The result is a machine with a reasonably improved design, higher average torque, lower torque ripple and smaller volume. In addition, the on-load Back-EMF is almost identical to the no-load one. Hence, the on-load cogging torque is almost identical to the no-load cogging torque.
\end{abstract}

Index Terms - Back-Electromotive Force (Back-EMF), Evolution Strategy, Frozen Permeability, Parametric Optimization, Permanent Magnet Synchronous Motor.

\section{INTRODUCTION}

The search for optimal design parameters during the design and manufacturing of electrical machines has been the focus of attention of numerous researchers, engineers and companies around the world. However, particularly in recent decades, optimization processes have been challenged and driven [1]-[5], on the one hand, by new requirements (new design techniques, new nonlinear materials, production cost, etc.) established by different standards around the world (NEMA, IEC 60034-30, IE1, IE2, IE3, IE4, IE5, NBR 17094-1, AS/NZS 1359.5-2004, etc.) for more efficient machines. On the other hand, these processes have been supported by the evolution of even faster computers, cloud computing, parallel processing and new analytical and numerical methods [6]-[11].

When it comes to the design optimization of permanent magnet synchronous machines (PMSM), the majority of published articles and procedures focus on reducing the electromagnetic torque ripple, a 
goal that includes loss reduction, less mechanical vibration and noise, greater reliability and reduced short, mid- and long-term maintenance.

One of the approaches most widely employed to optimize torque ripple reduction in PMSM is parametric optimization. This approach is focused on stator teeth dimensions (width, height, tooth-tip, tooth-shoes, slot-opening width, etc.) and stator yoke thickness, using Differential Evolution (DE) [7]; or on the shape and size of permanent magnets (PMs), using Topology Optimization (TO) [8]; or on rotor parameters and dimensions (including flux barriers - shape, position and dimensions) using Genetic Algorithms (GAs) and the Kriging Method (KM) [9]-[10].

However, the important role of the Back-EMF in PMSMs for torque production is neglected by numerous optimization methods, which also fail to involve inspections of the symmetry of windings in order to expedite the optimization process. One of few examples that accounts for the Back-EMF waveform during the optimization process is described by Liu et al. [6], who employ GAs to optimize the shape of PMs and flux barriers in order to improve torque production by enhancing PM flux linkage, and hence, the Back-EMF waveform.

The main reason for the dearth of optimization approaches based on on-load Back-EMF is due to the difficult task of separating the torque components, and particularly, the two components of the on-load flux linkage: PM and armature. However, since the advent of the Frozen Permeability (FP) method in the late 1990s [12], this task has been superseded by new, precise and robust methods aimed at improving on-load Back-EMF assessment, such as the Back-EMF MST method proposed by Paula et al., 2018 [13] and Paula, 2016 [14]. This method enables the machine designer to garner more information about the contribution of air-gap flux density to each tooth saturation level and its effect on the PM flux linkage, and thus, on the on-load Back-EMF.

This article describes the parametric optimization approach applied to a surface mounted permanent magnet synchronous machine (SM-PMSM) in order to reduce the torque ripple by reducing the sensitivity of the on-load Back-EMF to the increase of the electromagnetic load and to enhance its predictability, since the value and waveform of the on-load Back-EMF will be almost the same as those of the no-load Back-EMF (within a tolerance of 0.5\%). To this end, an Evolution Strategy [15]-[20] is adopted, along with the Back-EMF MST (which requires the FP method), to properly evaluate the onload Back-EMF and garner all the information required to optimize the tooth dimension.

This paper is organized as follows: Section II outlines the parameters and dimensions of the machine, while Section III discusses the optimization method, Section IV describes and discusses the results of three different case studies of the same machine, and lastly, Section V offers a general discussion and our conclusions.

\section{MACHINE PARAMETERS AND DIMENSIONS}

Table I describes the dimensions and characteristics of the SM-PMSM analyzed here, while Fig. 1 depicts a cross-section of the machine. 


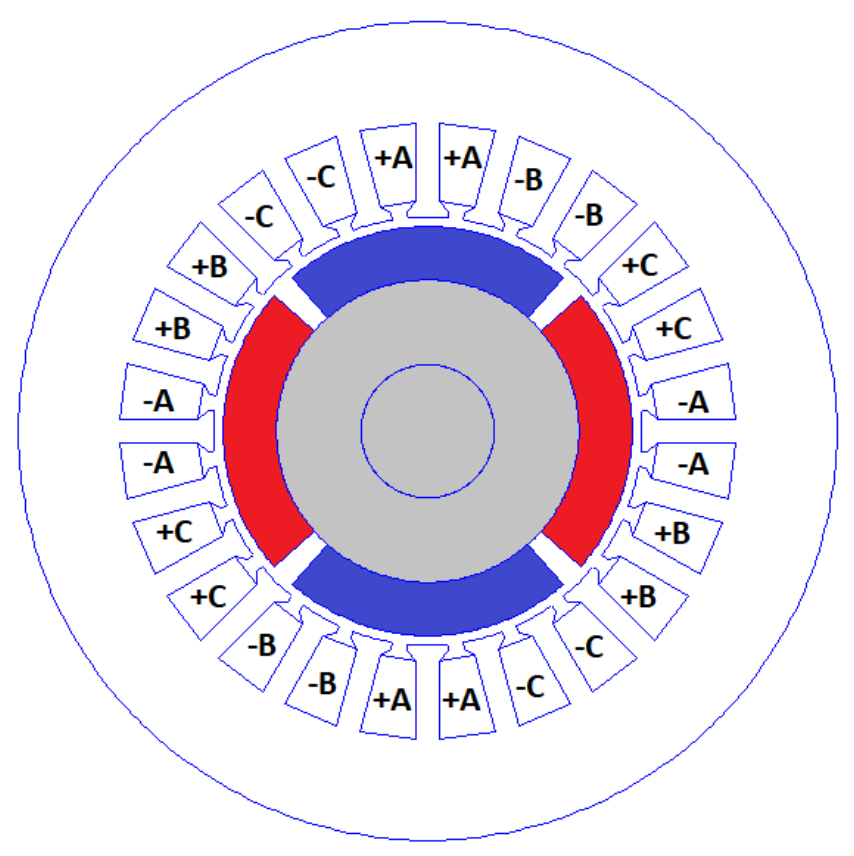

Fig. 1. SM-PMSM cross-section

TABLE I. MACHINE CHARACTERISTICS

\begin{tabular}{lc}
\hline \hline \multicolumn{1}{c}{ Parameters } & Dimensions \\
\hline Slot Number & 24 \\
Stator Outer Diameter & $116.6 \mathrm{~mm}$ \\
Stator Inner Diameter & $61 \mathrm{~mm}$ \\
Stator Yoke Thickness & $14.35 \mathrm{~mm}$ \\
Tooth Width (tw) & $3.52 \mathrm{~mm}$ \\
Slot Opening (tsw) & $2.15 \mathrm{~mm}$ \\
Stator Tooth Tip & $1 \mathrm{~mm}$ \\
Conductors Diameter & $21 \mathrm{AWG}$ \\
Pole Number & 4 \\
Air gap Length & $1.35 \mathrm{~mm}$ \\
Rotor Outer Diameter & $58.3 \mathrm{~mm}$ \\
Shaft Diameter & $19 \mathrm{~mm}$ \\
PM Thickness & $7.6 \mathrm{~mm}$ \\
PM Type & Ferrite \\
PM arc-span & $82.5^{\circ}$ \\
\hline \hline
\end{tabular}

It should be noted that the current waveform used to feed the machine armature during the simulation is a square waveform, which is employed to simulate a six-step operation. The reason for this choice is that the harmonic content of the square current waveform is greater than that of the sinusoidal current waveform. Hence, even when it produces the same average torque, the saturation effect is more intense and the torque ripple is usually higher. Therefore, a solution found during the optimization based on the square current waveform will also be suitable for the sinusoidal current waveform operation. In 
addition, the current peak value is $10 \mathrm{~A}$, which corresponds to the rated load condition of the machine.

\section{PROPOSED METHODOLOGY}

\section{A. Optimization Process}

As mentioned earlier, the main goal of this work is to carry out a parametric optimization on a SMPMSM, striving to keep the on-load and no-load Back-EMF waveforms similar to each other, i.e., to ensure that the on-load Back-EMF is less sensitive or even non-sensitive to the increase in electromagnetic load. As a result, the torque ripple is expected to decrease and the average torque value to increase.

Before beginning the machine optimization process, possible symmetries in the machine were analyzed in order to reduce the computational effort and keep the machine balanced. Since the machine in question has 4 poles and 24 slots, the implied symmetry that is visible is used to reduce the machine by $1 / 4$. Thus, the number of teeth under optimization is 6 , as illustrated in Fig. 2, in which the teeth are numbered for future reference.

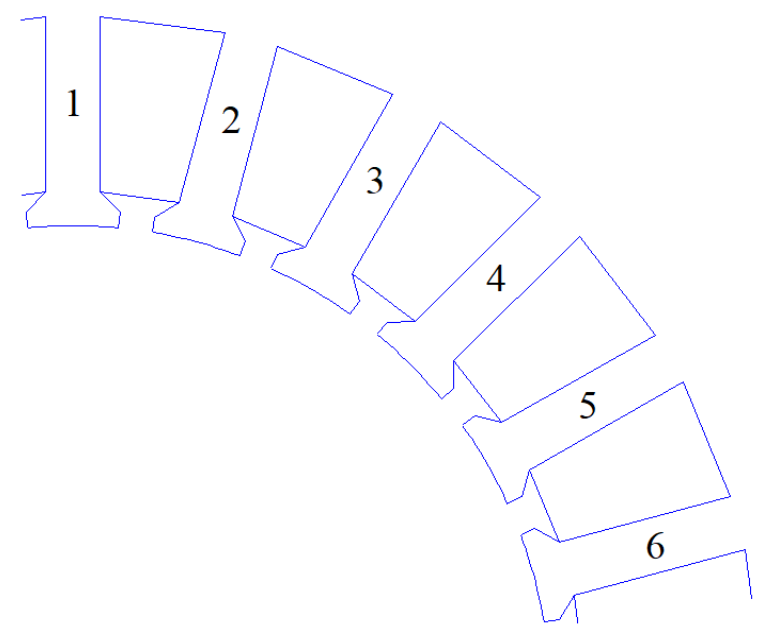

Fig. 2. Identification of stator teeth in $1 / 4$ of the machine stator

Although the aforementioned approach seems to be one of the most suitable ones to reduce computational time and effort, this paper considers another approach, which involves the optimization of only two stator teeth, as illustrated and numbered in Fig. 3.

The main reason for using this second approach is the fact that a previous test carried out during this research indicated that, during the optimization process of only one phase, which involved 6 teeth (as the first approach suggested), the Back-EMF waveform was moderately affected by the dimensions of only two of these six teeth. This point is discussed in greater detail in Section IV, which describes, discusses and compares the case studies. 


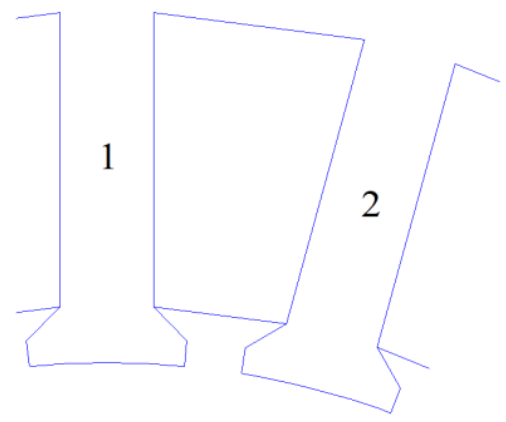

Fig. 3. Identification of stator teeth in the 2 teeth optimization approach

Another strategy adopted in this study involves the tooth symmetry.

1) Symmetric Set of Variables: in which tooth width (tw) and tooth shoes (tsw) are optimized (see Fig. 4a).

2) Asymmetric Set of Variables: where each tooth-related set of variables is split into two and rendered independent of its counterpart. Hence, there are tooth width 1 and 2 (tw1 and tw2) and tooth shoes 1 and 2 (tsw1 and tsw2), as illustrated in Fig. 4b.

Table II describes the range of design variables.

In addition, the stator outer diameter is also optimized to reduce the machine's volume, thereby reducing material and production costs.
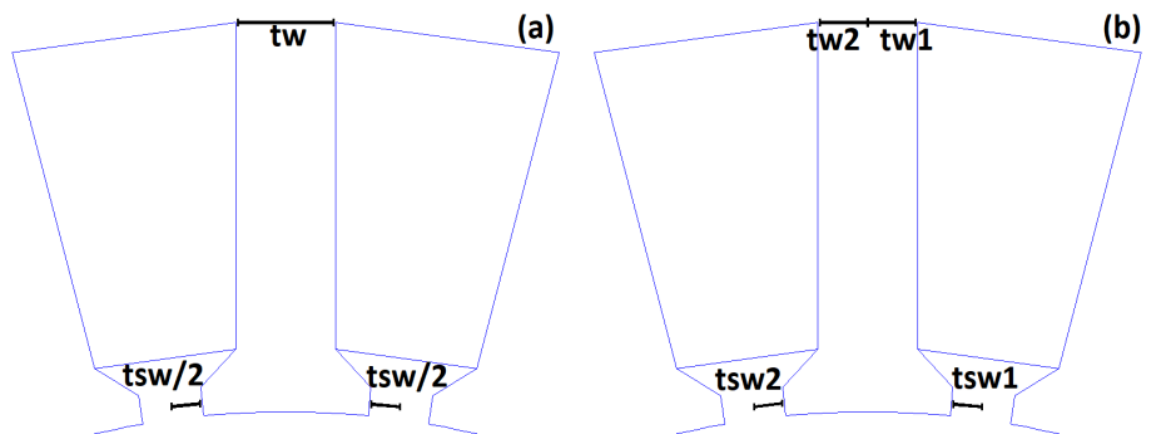

Fig. 4. Design Variables: (a) Symmetric set of variables; (b) Asymmetric set of variables

TABLE II. RANGE OF DESIGN VARIABLES

\begin{tabular}{ccc}
\hline \hline Variable & Minimum & Maximum \\
\hline tw (mm) & 2.520 & 4.520 \\
tsw (mm) & 1.150 & 2.150 \\
tw1 (mm) & 1.260 & 2.260 \\
tw2 (mm) & 1.260 & 2.260 \\
tsw1 (mm) & 0.575 & 1.075 \\
tsw2 (mm) & 0.575 & 1.075 \\
\hline
\end{tabular}

\section{B. Frozen Permeability and Back-EMF MST methods}

The Frozen Permeability (FP) method was proposed by Bianchi and Bolognani [12] to analyze electrical machines by linearizing the properties of nonlinear magnetic materials (particularly the Brazilian Microwave and Optoelectronics Society-SBMO received 29 Oct 2018; for review 1 Nov 2018; accepted 25 July 2019 
relative permeability) in stator and rotor at the operating point on the DC magnetization curve. Thus, the task of segregating the flux (PM and armature) and torque components, which is accomplished based on the fixed permeability, accounts for electromagnetic saturation.

The FP method is illustrated in Fig. 5 for a fictitious DC magnetization curve, where the material's relative permeability is assessed at the operating point (OP), and then fixed and saved to evaluate the contributions of PM and Armature to the total flux.

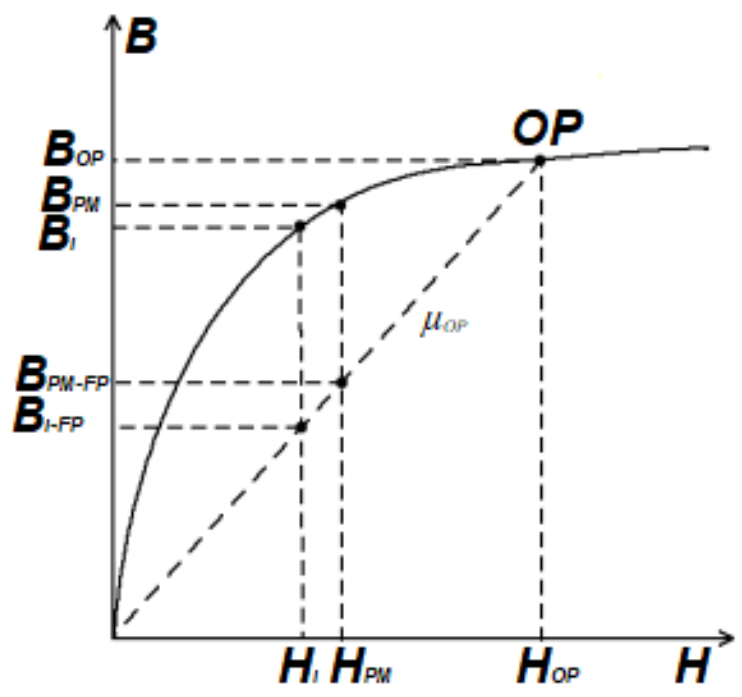

Fig. 5. Frozen Permeability method

If the FP method is not applied, the sum of the contributions of PM and Armature to the magnetic flux density ( $B_{P M}$ and $B_{i}$, respectively) does not result in the flux density of the operating point $\left(B_{O P}\right)$. However, the sum of the contributions of PM and Armature to the magnetic field intensity $\left(H_{P M}\right.$ and $H_{i}$, respectively) corresponds to the magnetic field intensity of the operating point $\left(H_{O P}\right)$.

On the other hand, in the FP method, since the relative permeability is fixed at the operating point $\left(\mu_{O P}\right)$, the magnetic flux densities due to the PM and Armature contributions are recalculated as a function of their respective magnetic field intensity $\left(H_{P M}\right.$ and $\left.H_{i}\right)$ and the $\mu_{O P}$. Now, the sum of the magnetic field intensities results in the magnetic field intensity at the operating point $\left(H_{O P}\right)$, and the sum of the magnetic flux densities $\left(B_{P M-F P}\right.$ and $\left.B_{i-F P}\right)$ results in the magnetic flux density at the operating point $\left(B_{O P}\right)$.

For the sake of clarity, the FP method involves the following steps:

1 - On-load simulation taking into account all the nonlinearities of the materials;

2 - Assessment of the relative permeability of each element in the finite element mesh, which is then fixed and saved;

3 - Linear simulation based on the fixed permeability. This simulation can be performed to evaluate the contribution of the armature (Armature only and PM off) or to evaluate the contribution of the PM (PM only, Armature off).

Although the FP method enables easy and accurate assessment of the on-load PM flux linkage, the evaluation of on-load Back-EMF based on the differentiation of the on-load PM flux linkage is less 
accurate and does not provide information about which tooth is saturated or on what part of the tooth the saturation occurs.

Therefore, in order to properly evaluate the on-load Back-EMF, Paula et al., 2018 [13] and Paula, 2016 [14] proposed the Back-EMF MST method. This method, which combines the FEM, MST and FP methods to express the on-load Back-EMF based on the on-load flux density distribution, has been validated with $0.1 \%$ of accuracy.

The electromagnetic torque $\left(T_{E L}\right)$ of a PM machine is composed of the PM torque $\left(T_{P M}\right)$, which is due to the interaction of the armature current and the Back-EMFs; the reluctance torque $\left(T_{R E L}\right)$, which is due to inductance variations; and the cogging torque $\left(T_{C o g}\right)$, which is an intrinsic characteristic of this type of machine and involves the interaction of the slot opening and the rotor pole edges. The reluctance torque of surface mounted PM machines can be neglected even in the condition of high electric loads.

Based on the Maxwell stress tensor, the electromagnetic torque $\left(T_{E L}\right)$ can be expressed as (1):

$$
T_{E L}=\frac{l_{f e}}{\mu_{0}} \int_{0}^{2 \pi} r^{2}\left(B_{O P}\right)_{R}\left(B_{O P}\right)_{T} d \theta
$$

where the subscripts $R$ and $T$ correspond to the radial and tangential components of the function delimited by the brackets, $l_{f e}$ is the active axial length of the electrical machine, $\mu_{0}$ is the permeability of free space, and $r$ is the radius associated with the middle of the air gap.

According to the FP method, the magnetic flux density of the operating point $\left(B_{O P}\right)$ is the sum of the contributions from PM and Armature $\left(B_{P M-F P}\right.$ and $\left.B_{i-F P}\right)$; hence, (1) can be rewritten as (2):

$$
T_{E L}=\frac{l_{f e}}{\mu_{0}} \int_{0}^{2 \pi} r^{2}\left[\begin{array}{l}
\left(B_{P M-F P}\right)_{R}\left(B_{i-F P}\right)_{T}+\left(B_{i-F P}\right)_{R}\left(B_{P M-F P}\right)_{T} \\
+\left(B_{i-F P}\right)_{R}\left(B_{i-F P}\right)_{T}+\left(B_{P M-F P}\right)_{R}\left(B_{P M-F P}\right)_{T}
\end{array}\right] d \theta
$$

Since the PM torque is produced by the interaction between the armature current and the Back-EMF, it can be concluded from (2) that the $T_{P M}$ is as shown in (3):

$$
T_{P M}=\frac{l_{f e}}{\mu_{0}} \int_{0}^{2 \pi} r^{2}\left[\left(B_{P M-F P}\right)_{R}\left(B_{i-F P}\right)_{T}+\left(B_{i-F P}\right)_{R}\left(B_{P M-F P}\right)_{T}\right] d \theta
$$

However, the $T_{P M}$ can also be expressed as (4):

$$
T_{P M}=i_{A}(\theta) e_{A}(\theta)+i_{B}(\theta) e_{B}(\theta)+i_{C}(\theta) e_{C}(\theta)
$$

where $e_{A}, e_{B}$ and $e_{C}$ are the speed normalized on-load Back-EMFs for phases A, B and C, respectively; and $i_{A}, i_{B}$ and $i_{C}$ are the currents of phases $\mathrm{A}, \mathrm{B}$ and $\mathrm{C}$, respectively.

With the aid of the FP method, the contribution of the armature can also be seen as the sum of the contribution of each phase current, as indicated in (5).

$$
B_{i-F P}=B_{i-F P_{-} A}+B_{i-F P_{-} B}+B_{i-F P_{-} C}
$$

where subscripts $\_A, \_B$ and $\_C$ stand for the contribution of phases $\mathrm{A}, \mathrm{B}$ and $\mathrm{C}$, respectively.

Substituting (5) in (3) results in (6): 


$$
\begin{aligned}
T_{P M}= & \frac{l_{f e}}{\mu_{0}} \int_{0}^{2 \pi} r^{2}\left[\left(B_{P M-F P}\right)_{R}\left(B_{i-F P_{-} A}\right)_{T}+\left(B_{i-F P_{-} A}\right)_{R}\left(B_{P M-F P}\right)_{T}\right] d \theta \\
& +\frac{l_{f e}}{\mu_{0}} \int_{0}^{2 \pi} r^{2}\left[\left(B_{P M-F P}\right)_{R}\left(B_{i-F P_{-} B}\right)_{T}+\left(B_{i-F P_{-} B}\right)_{R}\left(B_{P M-F P}\right)_{T}\right] d \theta \\
& +\frac{l_{f e}}{\mu_{0}} \int_{0}^{2 \pi} r^{2}\left[\left(B_{P M-F P}\right)_{R}\left(B_{i-F P_{-} C}\right)_{T}+\left(B_{i-F P_{-} B}\right)_{R}\left(B_{P M-F P}\right)_{T}\right] d \theta
\end{aligned}
$$

A comparison of (6) and (4) leads to (7):

$$
\begin{aligned}
& i_{A}(\theta) e_{A}(\theta)=\frac{l_{f e}}{\mu_{0}} \int_{0}^{2 \pi} r^{2}\left[\left(B_{P M-F P}\right)_{R}\left(B_{i-F P_{-} A}\right)_{T}+\left(B_{i-F P_{-} A}\right)_{R}\left(B_{P M-F P}\right)_{T}\right] d \theta \\
& i_{B}(\theta) e_{B}(\theta)=\frac{l_{f e}}{\mu_{0}} \int_{0}^{2 \pi} r^{2}\left[\left(B_{P M-F P}\right)_{R}\left(B_{i-F P_{-} B}\right)_{T}+\left(B_{i-F P_{-} B}\right)_{R}\left(B_{P M-F P}\right)_{T}\right] d \theta \\
& i_{C}(\theta) e_{C}(\theta)=\frac{l_{f e}}{\mu_{0}} \int_{0}^{2 \pi} r^{2}\left[\left(B_{P M-F P}\right)_{R}\left(B_{i-F P_{-} C}\right)_{T}+\left(B_{i-F P_{-} B}\right)_{R}\left(B_{P M-F P}\right)_{T}\right] d \theta
\end{aligned}
$$

Therefore, if a unity phase current is applied after the linearization proposed by the FP method, the speed normalized on-load Back-EMF can be assessed using the Maxwell stress tensor. For example, the speed normalized on-load Back-EMF of phase A is written as (8):

$$
e_{A}(\theta)=\frac{l_{f e}}{\mu_{0}} \int_{0}^{2 \pi} r^{2}\left[\left(B_{P M-F P}\right)_{R}\left(B_{i-F P_{-} A}\right)_{T}+\left(B_{i-F P_{-} A}\right)_{R}\left(B_{P M-F P}\right)_{T}\right] d \theta
$$

To assess all the Back-EMFs of a three phase PM machine, which is the case of the machine examined here, step 3 of the FP method must be carried out four times: once for the PM contribution ( $B_{P M-F P}$, radial and tangential contributions in the middle of the air gap); and three times for the Armature contribution ( $B_{i-F P}$, radial and tangential contributions in the middle of the air gap for each phase).

\section{Evolution Strategy}

In this study, the Evolution Strategy (ES) method is employed mainly due to its ability to adapt a candidate solution to an objective function. This adaptation is done by means of self-adaptive parameters, which leads the optimization of the parameters [15]-[20].

The structure of a candidate solution, $X^{A}$, is expressed in (9) [17]-[18], where superscript $A$ is the candidate A; $x$ stands for the optimization parameters, which consist of $n$ structural variables; and $\sigma$ stands for their self-adaptive parameters.

$$
X^{A}=\left[x_{1}^{A} x_{2}^{A} x_{3}^{A} \mathrm{~K} x_{n}^{A} \mid \sigma_{1}^{A} \sigma_{2}^{A} \sigma_{3}^{A} \mathrm{~K} \sigma_{n}^{A}\right]
$$

The population is composed of $\mu$ candidates, expressed as (9), whose performance is evaluated according to the objective function. The candidate solutions are then combined in pairs by means of a local recombination, as expressed in (10) [18], [21], generating $\lambda$ descendants of the total population,

$$
X^{\prime}=\alpha X^{A}+(1-\alpha) X^{B}
$$

where $\alpha$ is a random number, $0 \leq \alpha \leq 1$, which is generated for each recombination; and superscript $B$ is the candidate $B$.

In the next step, the mutation process is performed in the $\lambda$ descendants generated by means of (10). 
The mutation process of the self-adaptive parameters $(\sigma)$ is expressed in (11), whereas the mutation process of the optimization parameters $(x)$ is expressed in (12),

$$
\begin{gathered}
\sigma_{i}^{t+1}=\sigma_{i}^{t} e^{\left(\tau^{\prime} N(0,1)+\tau . N_{i}(0,1)\right)} \\
\tau^{\prime} \propto(2 n)^{-1 / 2} \mathrm{~L} \tau \propto(4 n)^{-1 / 4} \\
x_{i}^{t+1}=x_{i}^{t}+\sigma_{i}^{t+1} N_{i}(0,1)
\end{gathered}
$$

where $i=1, \ldots, n$; and $N(0,1)$ represents a normal distribution with standard deviation equal to 1 and an average value equal to 0 [19]-[22]; and $t$ refers to the individual of the total population. The mutation of the self-adaptive parameter $\sigma$ is based on the log-normal adaptation strategy, whereby the global agent $\tau^{\prime}$ completely modifies the mutability of its parameters, and the local agent $\tau$ provides individual changes in the step sizes [22]-[23].

Lastly, all the candidates $(\mu+\lambda)$ pass through the recombination and the mutation process. The best candidates are then selected according to the objective function.

The flowchart in Fig. 6 illustrates the optimization process step by step.

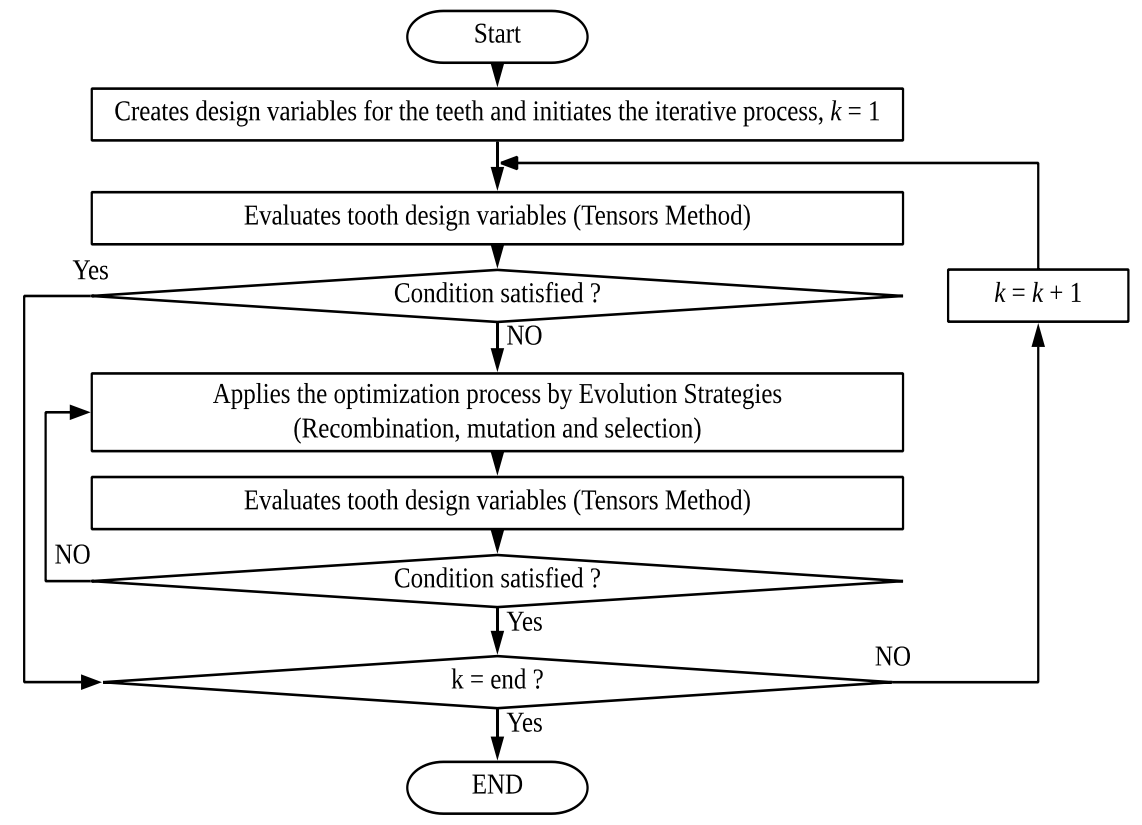

Fig. 6. Optimization process

The parameters of the Evolution Strategy method were defined as:

- Population Size - 10 individuals (or solutions);

- Self-adaptive - Activated;

- Recombination Rate-70\%;

- Mutation Rate-70\%.

It should be noted that the ES parameters adopted here were taken from the best results obtained Jesus \& Brito, 2017 [15], and that they have been adjusted to find the best solutions for optimizing the machine under investigation. 


\section{CASE STUDIES AND RESULTS}

As mentioned earlier herein, this study employed the parametric optimization approach, using the Evolution Strategy to reduce the torque ripple by making the on-load Back-EMF similar to the no-load Back-EMF (within a $0.5 \%$ tolerance). For the sake of clarity, the load condition considered is the machine's rated current, 10A.

The investigation was divided into three case studies:

1 - Optimization of 6 stator teeth ( $1 / 4$ of the machine) with a symmetric set of variables, whose shape and dimensions are replicated in the remaining $3 / 4$ of the machine.

2 - Optimization of 2 stator teeth with a symmetric set of variables.

3 - Optimization of 2 stator teeth with an asymmetric set of variables.

In each case, the stator outer diameter has been considered as an optimization variable, aiming to reduce the machine's volume and material, and therefore, its production cost. Obviously, there is a limit to the reduction of the stator's outer diameter, otherwise the machine's performance would be affected, since a thin stator yoke increases the saturation effect.

Note that the optimization process is carried out using 2D FEM simulation of 1/6th of the electrical period. All the simulations are performed on an Intel ${ }^{\circledR}$ Core $^{\mathrm{TM}}$ i7-4510U CPU, 2.60GHz, $8.00 \mathrm{~GB}$ RAM, without parallel computing.

\section{A. Case 1}

In this case, only a symmetric set of variables were considered and the time spent on this optimization was $7 \mathrm{~h} 07 \mathrm{~min}$. The machine's volume was reduced from $275.08 \mathrm{~cm}^{3}$ to $197.54 \mathrm{~cm}^{3}$, since the outer diameter of the stator was reduced from $116.6 \mathrm{~mm}$ to $106.6 \mathrm{~mm}$. Tables III and IV describe the initial and optimized dimensions of the tooth width (tw) and tooth shoes (tsw).

TABLE III. INITIAL PARAMETERS - CASE 1

\begin{tabular}{lcccccc}
\hline \hline \multicolumn{1}{c}{ Tooth } & $\mathbf{1}$ & $\mathbf{2}$ & $\mathbf{3}$ & $\mathbf{4}$ & $\mathbf{5}$ & $\mathbf{6}$ \\
\hline tw $(\mathrm{mm})$ & 3.520 & 3.520 & 3.520 & 3.520 & 3.520 & 3.520 \\
tsw $(\mathrm{mm})$ & 2.150 & 2.150 & 2.150 & 2.150 & 2.150 & 2.150 \\
\hline \hline
\end{tabular}

TABLE IV. OPTIMIZED PARAMETERS - CASE 1

\begin{tabular}{lcccccc}
\hline \hline Tooth & $\mathbf{1}$ & $\mathbf{2}$ & $\mathbf{3}$ & $\mathbf{4}$ & $\mathbf{5}$ & $\mathbf{6}$ \\
\hline $\mathrm{tw}(\mathrm{mm})$ & 3.688 & 4.347 & 3.549 & 4.080 & 3.142 & 4.442 \\
$\mathrm{tsw}(\mathrm{mm})$ & 2.017 & 2.040 & 2.132 & 2.020 & 2.009 & 1.966 \\
\hline \hline
\end{tabular}

Although all the teeth have different dimensions (see Table IV), there is a clearly visible pattern, i.e., the even teeth are wider than the odd teeth, and the dimensions of the even teeth are similar to each other. The odd teeth show the same similarity. These similarities suggest that the optimization process can be carried out using just two teeth.

The accuracy of this statement was confirmed by the authors in the investigation of a special 
optimization case, in which only one phase was optimized (phase A), i.e., the dimensions of only three of six teeth were changed by the optimization process (teeth 1,2 and 6). Then, when another phase was optimized (phase B, only), the results indicated that the dimensions of teeth 2, 3 and 4 were altered. Moreover, when only phase $\mathrm{C}$ was optimized, the teeth were 4, 5 and 6. Therefore, although three teeth were affected by the optimization process when only one phase was chosen, two of the three teeth were shared with the other two phases, i.e., phase A shared tooth no. 2 with phase B and tooth no. 6 with phase $\mathrm{C}$. Thus, given that each phase has only one tooth that is independent of what happens in the other phases, and when the optimization is carried out considering the three phases, the number of teeth under analysis can be reduced from six to two.

Another point that weighs against the results listed in Table IV is the increase in noise and vibration due to the different teeth structures presented in the optimized project, the low unbalanced phase voltages (although the Back-EMF was optimized to within a tolerance of $0.5 \%$, they are not identical in all the phases), and the higher cost involved in building such a machine, rendering it economically unattractive.

The Fig. 7 compares the on-load Back-EMFs of the initial machine and the optimized machine with the no-load one. A zoom-in view of the flat area of the Back-EMF highlights the differences between the waveforms, since this area is the most relevant one for torque production.

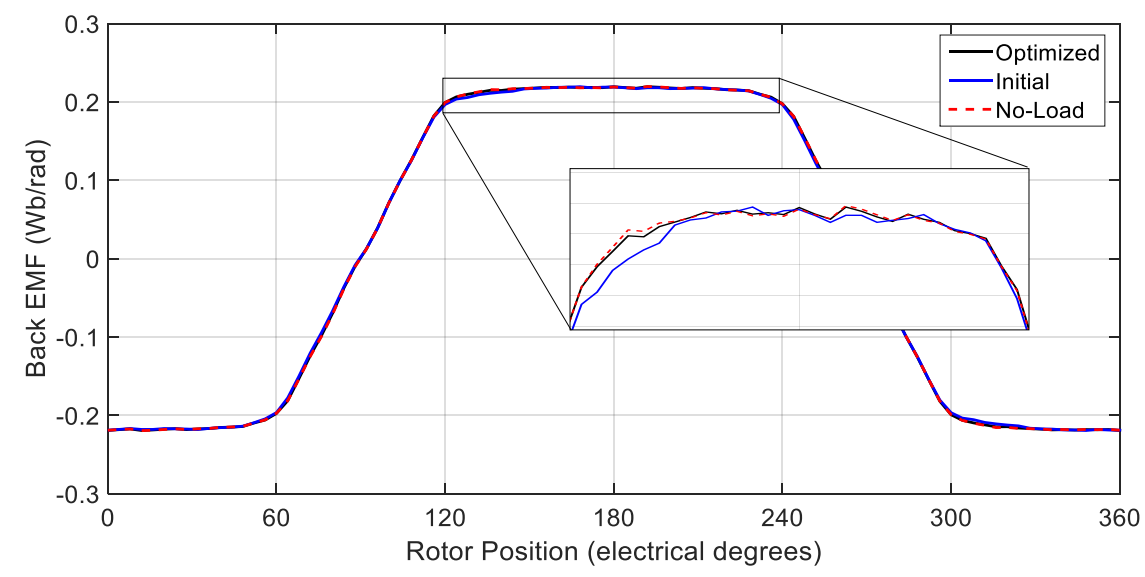

Fig. 7. Comparison of Back-EMFs - Case 1

It should be noted that the on-load Back-EMF of the optimized machine differs from the no-load Back-EMF by $0.47 \%$ in the worst case (albeit within the tolerance established for the optimization process), while the initial machine presents an on-load Back-EMF that differs from the no-load BackEMF by $2.23 \%$ in the worst case. Thus, the optimized machine can be expected to show a higher torque and lower torque ripple.

A tight tolerance could be applied to ensure the on-load Back-EMF and no-load Back-EMF are identical, but this would require in a much higher computational effort.

The torque of the optimized and initial machines was evaluated at the rated electric load (10A), as can be seen in Fig. 8. 
Journal of Microwaves, Optoelectronics and Electromagnetic Applications, Vol. 18, No. 3, September 2019369 DOI: http://dx.doi.org/10.1590/2179-10742019v18i31511

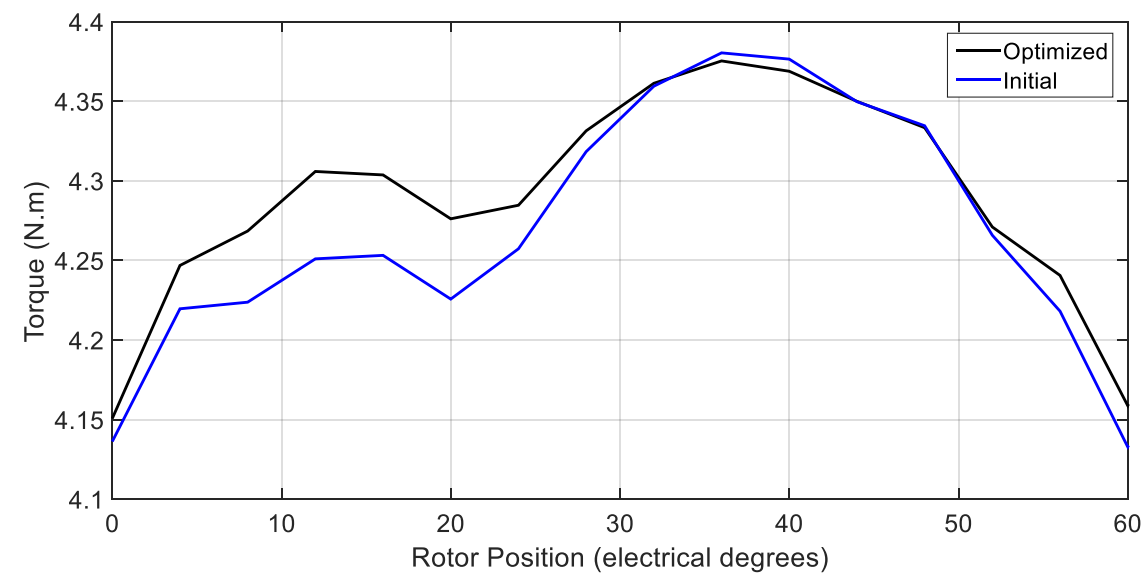

Fig. 8. Comparison of electromagnetic torque - Case 1

Table V lists the maximum, minimum, average and RMS torque values of the initial and optimized machines. As expected, the optimized machine shows a lower torque ripple (5.72\%).

TABLE V. COMPARISON OF ELECTROMAGNETIC TORQUE - CASE 1

\begin{tabular}{lcccc}
\hline \hline & Max & Min & AVG & RMS \\
\hline Initial (N.m) & 4.386 & 4.133 & 4.279 & 4.280 \\
Optimized (N.m) & 4.397 & 4.150 & 4.304 & 4.305 \\
\hline \hline
\end{tabular}

\section{B. Case 2}

In Case 2, only two teeth with a symmetric set of variables were considered, and the time spent on this optimization was $2 \mathrm{~h} 56 \mathrm{~min}$. The machine's volume was reduced from $275.08 \mathrm{~cm}^{3}$ to $194.92 \mathrm{~cm}^{3}$, since the outer diameter of the stator was reduced from $116.6 \mathrm{~mm}$ to $106.6 \mathrm{~mm}$. Tables VI and VII describe the initial and optimized dimensions of the tooth width (tw) and tooth shoes (tsw).

Unlike the problem of unbalanced phase voltages found in Case 1, all the on-load three phase Back-EMFs are identical here. Furthermore, the teeth structure of this case was much easier to build, making it more cost-attractive than Case 1.

TABLE VI. INITIAL PARAMETERS - CASE 2

\begin{tabular}{rcc}
\hline \hline Tooth & $\mathbf{1}$ & $\mathbf{2}$ \\
\hline tw $(\mathrm{mm})$ & 3.520 & 3.520 \\
tsw $(\mathrm{mm})$ & 2.150 & 2.150 \\
\hline \hline
\end{tabular}

TABLE VII. OPTIMIZED PARAMETERS - CASE 2

\begin{tabular}{ccc}
\hline \hline Tooth & $\mathbf{1}$ & $\mathbf{2}$ \\
\hline tw $(\mathrm{mm})$ & 2.867 & 4.477 \\
tsw $(\mathrm{mm})$ & 2.150 & 2.090 \\
\hline \hline
\end{tabular}

The Fig. 9 compares the on-load Back-EMFs of the initial and optimized machines with the no-load ones. Again, a zoom-in view of the flat area of the Back-EMF highlights the differences between the 
Journal of Microwaves, Optoelectronics and Electromagnetic Applications, Vol. 18, No. 3, September 2019370 DOI: http://dx.doi.org/10.1590/2179-10742019v18i31511

waveforms, since this area is the most relevant one for torque production.

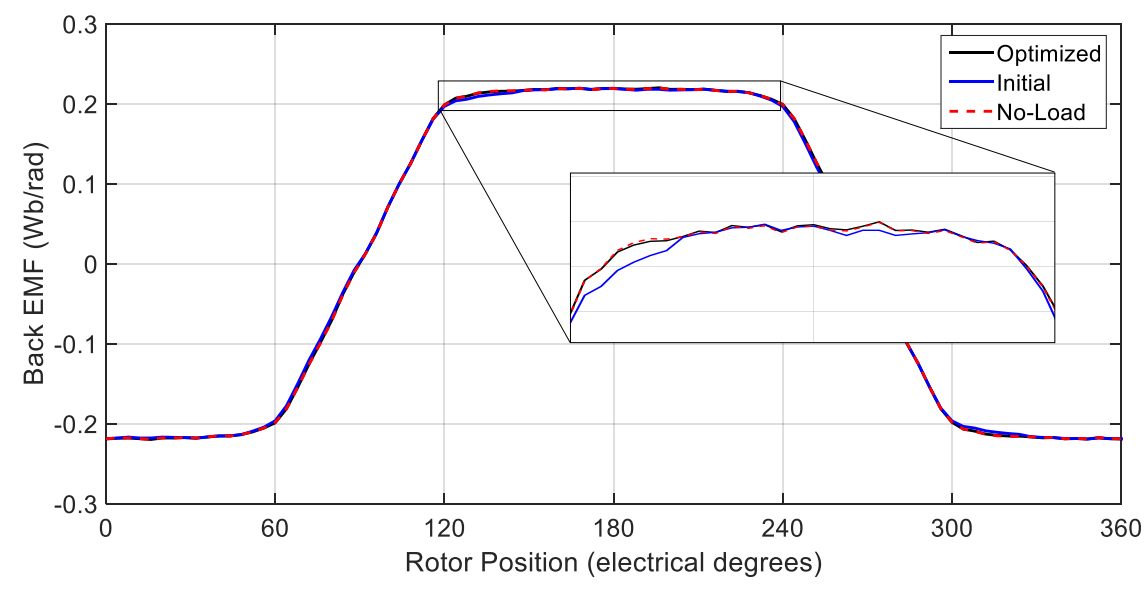

Fig. 9. Comparison of Back-EMFs - Case 2

While Case 1 presented a difference of $0.47 \%$ in the worst case when compared to the no-load one, the difference here was $0.36 \%$, indicating that this strategy was effective in reducing the computational effort and even in improving the on-load Back-EMF. Moreover, a lower torque ripple and a higher torque value were expected when compared to those of Case 1 and the initial machine.

Once again, a tight tolerance could be applied to effectively render the on-load Back-EMF identical to the no-load Back-EMF, although this would increase the computational effort.

The torque of the optimized and initial machines were evaluated at the rated electric load (10A), as indicated in Fig. 10.

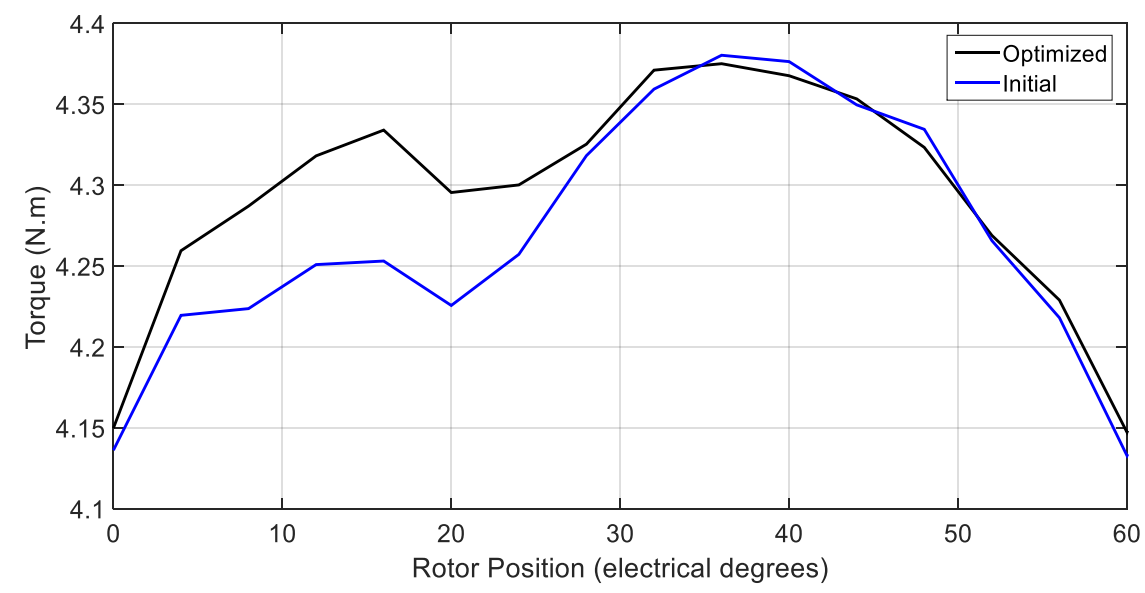

Fig. 10. Comparison of electromagnetic torque - Case 2

Table VIII lists the maximum, minimum, average and RMS torque values of the initial and optimized machines. As expected, the optimized machine showed a lower torque ripple (5.44\%).

TABLE VIII. COMPARISON OF ELECTROMAGNETIC TORQUE - CASE 2

\begin{tabular}{lcccc}
\hline \hline & Max & Min & AVG & RMS \\
\hline Initial (N.m) & 4.386 & 4.133 & 4.279 & 4.280 \\
Optimized (N.m) & 4.381 & 4.147 & 4.302 & 4.303 \\
\hline \hline
\end{tabular}


Journal of Microwaves, Optoelectronics and Electromagnetic Applications, Vol. 18, No. 3, September 2019371 DOI: http://dx.doi.org/10.1590/2179-10742019v18i31511

\section{Case 3}

In Case 3, only two teeth with an asymmetric set of variables (tw1, tw2, tsw1 and tsw2) were considered, and the time spent on this optimization was $5 \mathrm{~h} 58 \mathrm{~min}$. The machine's volume was reduced from $275.08 \mathrm{~cm}^{3}$ to $196.5 \mathrm{~cm}^{3}$, since the outer diameter of the stator was reduced from $116.6 \mathrm{~mm}$ to 106.6 mm. Tables IX and X describe the initial and optimized dimensions of the tooth width (tw1 and tw2) and tooth shoes (tsw1 and tsw2).

The on-load Back-EMFs of the initial and optimized machines are compared with the no-load BackEMF in Fig. 11. A zoom-in view of the flat area of the Back-EMF highlights the differences between the waveforms, since this area is the most relevant one for torque production.

TABLE IX. INITIAL PARAMETERS - CASE 3

\begin{tabular}{rcc}
\hline \hline Tooth & $\mathbf{1}$ & $\mathbf{2}$ \\
\hline tw1 $(\mathrm{mm})$ & 1.760 & 1.760 \\
tw2 $(\mathrm{mm})$ & 1.760 & 1.760 \\
tsw1 $(\mathrm{mm})$ & 1.075 & 1.075 \\
tsw2 $(\mathrm{mm})$ & 1.075 & 1.075 \\
\hline \hline
\end{tabular}

TABLE X. OPTIMIZED PARAMETERS - CASE 3

\begin{tabular}{ccc}
\hline \hline Tooth & $\mathbf{1}$ & $\mathbf{2}$ \\
\hline tw1 $(\mathrm{mm})$ & 1.667 & 2.227 \\
tw2 $(\mathrm{mm})$ & 1.433 & 2.260 \\
tsw1 $(\mathrm{mm})$ & 0.950 & 1.075 \\
tsw2 $(\mathrm{mm})$ & 1.073 & 1.075 \\
\hline \hline
\end{tabular}

While Case 2 presents a difference of $0.36 \%$ in the worst case when compared to the no-load one, the difference here is $0.27 \%$, indicating that this strategy improved the on-load Back-EMF but increased the computational effort and the time spent when compared to Case 2.

The torque of the optimized and initial machines were evaluated at the rated electric load (10A), as illustrated in Fig. 12.

Table XI lists the maximum, minimum, average and RMS torque values of the initial and optimized machines. As expected, the optimized machine showed a lower torque ripple $(5.59 \%)$ than those of Case 1 and the initial machine, but a higher torque ripple when compared to Case 2.

TABle XI. Comparison OF ELECTROMAGNeTiC TORQUe - CASE 3

\begin{tabular}{lcccc}
\hline \hline & Max & Min & AVG & RMS \\
\hline Initial (N.m) & 4.386 & 4.133 & 4.279 & 4.280 \\
Optimized (N.m) & 4.395 & 4.154 & 4.313 & 4.314 \\
\hline \hline
\end{tabular}


Journal of Microwaves, Optoelectronics and Electromagnetic Applications, Vol. 18, No. 3, September 2019372 DOI: http://dx.doi.org/10.1590/2179-10742019v18i31511

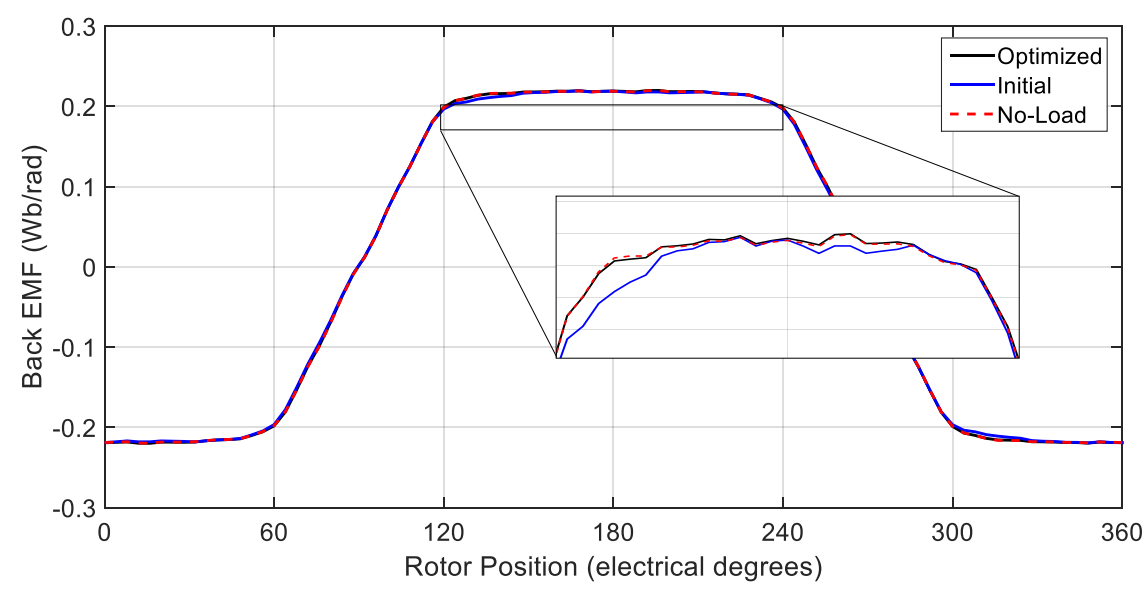

Fig. 11. Comparison of Back-EMFs - Case 3

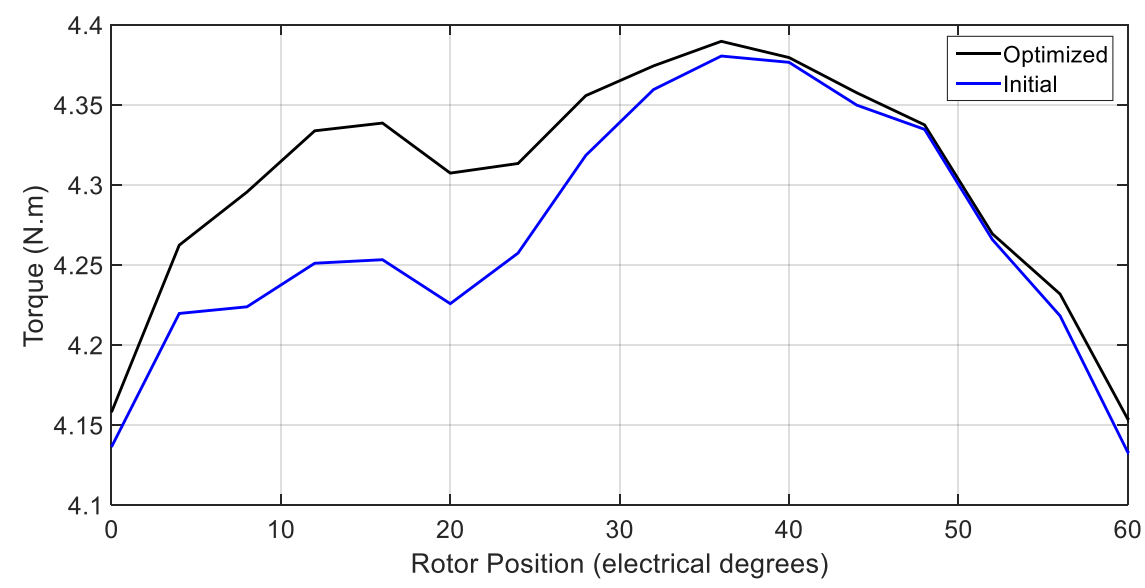

Fig. 12. Comparison of electromagnetic torque - Case 3

\section{Overall Comparison}

This subsection summarizes and compares the results of the case studies. The first comparison is based on Fig. 13, which illustrates the optimized Back-EMFs and the no-load Back-EMF. The on-load Back-EMF of all the optimized cases is similar to the no-load one, within a tolerance range of $0.5 \%$.

Although the goal in all the cases was the same, the $0.5 \%$ tolerance range enabled them to converge towards a different result that directly affects the torque production (average torque and torque ripple).

The Fig. 14 illustrates the electromagnetic torque of the three cases and of the initial machine. Note that although Case 3 offers the best optimization solution, i.e., higher average torque, it requires a higher computational effort than Case 2.

Table XII describes the time spent on each optimization, the machine's initial and optimized volume, and the difference between the optimized on-load Back-EMF and the no-load Back-EMF. As can be seen, although the on-load Back-EMF of Case 3 reached the smallest difference, its computation time was almost twice that of Case 2. 
Journal of Microwaves, Optoelectronics and Electromagnetic Applications, Vol. 18, No. 3, September 2019373 DOI: http://dx.doi.org/10.1590/2179-10742019v18i31511

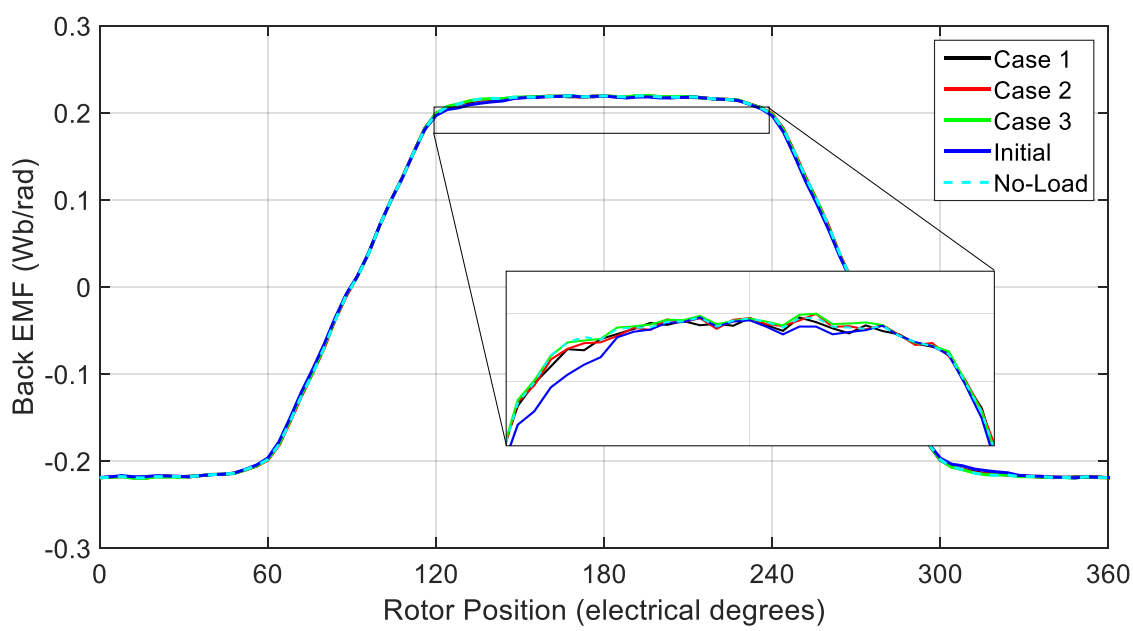

Fig. 13. Comparison of Back-EMFs of all the cases

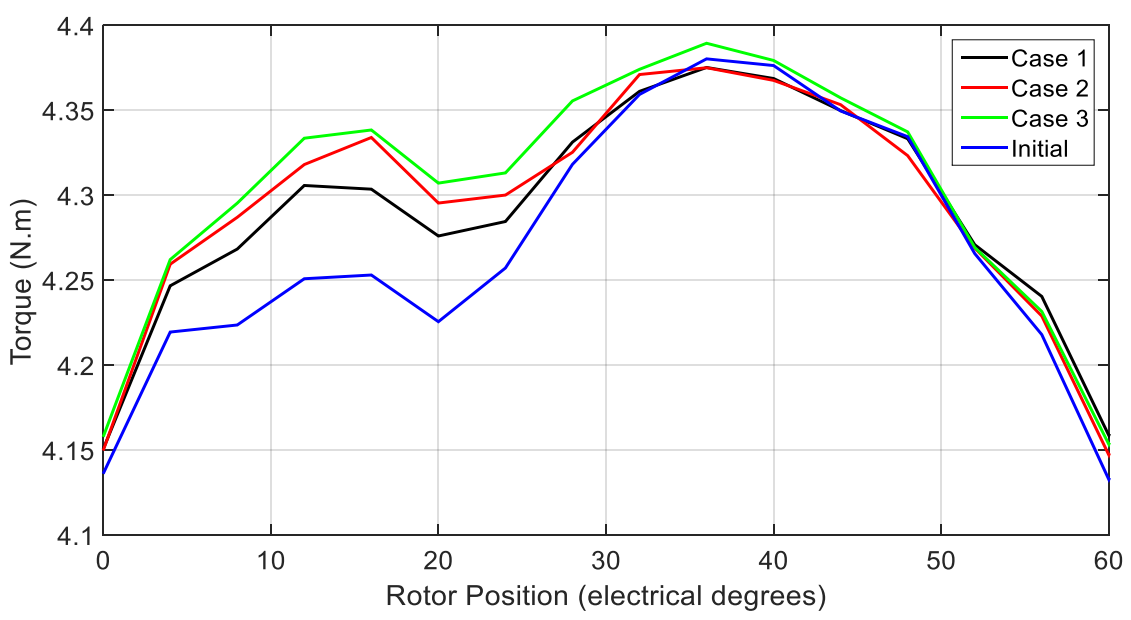

Fig. 14. Electromagnetic torque

TABLE XII. OPTIMIZATION RESUltS

\begin{tabular}{lccc}
\hline \hline & Difference (\%) & $\begin{array}{c}\text { Optimization } \\
\text { Time }\end{array}$ & $\begin{array}{c}\text { Volume } \\
\left(\mathbf{c m}^{3}\right)\end{array}$ \\
\hline Initial & - & - & 275.08 \\
Case 1 & 0.47 & $07 \mathrm{~h} 07 \mathrm{~min}$ & 197.54 \\
Case 2 & 0.36 & $02 \mathrm{~h} 56 \mathrm{~min}$ & 194.92 \\
Case 3 & 0.27 & $05 \mathrm{~h} 58 \mathrm{~min}$ & 196.50 \\
\hline \hline
\end{tabular}

Table XIII describes the torque ripple of each case and that of the initial machine. The torque ripple assessed throughout this paper is based on (13) [6], [10],

$$
T_{\text {ripple }}(\%)=\frac{T_{\max }-T_{\min }}{T_{A V G}} .100
$$

where $T_{\text {ripple }}(\%)$ is the percentage of torque ripple, $T_{\max }$ is the maximum torque, $T_{\min }$ is the minimum torque and $T_{A V G}$ is the average torque. 
Journal of Microwaves, Optoelectronics and Electromagnetic Applications, Vol. 18, No. 3, September 2019374 DOI: http://dx.doi.org/10.1590/2179-10742019v18i31511

TABLE XIII. COMPARISON OF TORQUE RIPPLE

\begin{tabular}{lcc}
\hline \hline & Torque Ripple (\%) & Reduction $(\%)$ \\
\hline Initial & 5.92 & - \\
Case 1 & 5.72 & 3.22 \\
Case 2 & 5.44 & 8.05 \\
Case 3 & 5.59 & 5.30 \\
\hline \hline
\end{tabular}

The strategy of optimizing the on-load Back-EMF so as to reduce its sensitivity to the increase of the electric load directly affected the cogging torque waveform, as can be seen in Fig. 15, which compares the no-load cogging torque to the on-load cogging torque of the initial and optimized machines.

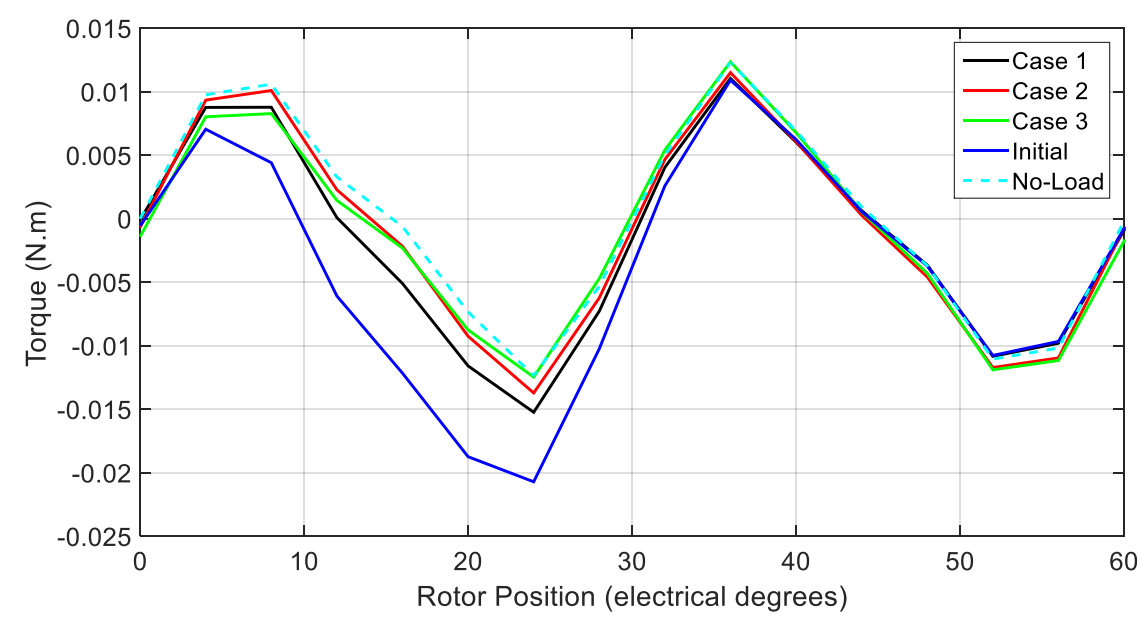

Fig. 15.Cogging Torque

Therefore, the solution found for the Back-EMF reduces the sensitivity to load increases of both the Back-EMF and the cogging torque. This is a very important point for machine control designers, since all the parameters of the machine can be considered constant within a wide operating range.

On the other hand, an attention must be paid if the machine under evaluation is an Interior Permanent Magnet Synchronous Machine (IPMSM) since for this type of machine the inductance and reluctance torque cannot be neglected and will be reasonably affected by the optimization process proposed here. If applied on IPMSM, the results of the proposed optimization process will show that on-load Back-EMF can be kept similar to the no-load Back-EMF but the cogging torque, reluctance torque and inductance will be reasonably affected. This effect lies on the fact that the Back-EMF is based on the armature and PM contribution in the flux density distribution ( $\mathrm{B}_{\mathrm{i}-\mathrm{FP}}$ and $\left.\mathrm{B}_{\mathrm{PM}-\mathrm{FP}}\right)(8)$, which leads the optimization algorithm to deal with two variables that are sensitive to an increase in the electric load. In SM-PMSM, this effect does not occur because the Back-EMF is not as sensitive to $\mathrm{B}_{\mathrm{i}-\mathrm{FP}}$ as it is in IPMSM, although it is still expressed as a function of $\mathrm{B}_{\mathrm{i}-\mathrm{FP}}(8)$.

\section{CONCLUSIONS}

This study employed the recent on-load Back-EMF assessment method [13] (called Back-EMF MST) along with the Evolution Strategy to reduce the sensitivity of the on-load Back-EMF to electric load 
increases. As discussed in Section IV, three different cases were studied, considering different stator and teeth symmetries: 6 teeth with a symmetric set of variables, 2 teeth with a symmetric set of variables and 2 teeth with an asymmetric set of variables.

Although the optimization process was carried out considering a tolerance of $0.5 \%$, each case presented a different computational effort and overall performance. The most promising result was achieved in Case 2, which resulted in a difference of $0.36 \%$ between the on-load and no-load BackEMFs and also contributed to the lowest torque ripple. Moreover, Case 2 represented the most costeffective construction of teeth and stator structure.

The last point to be highlighted is the on-load cogging torque, which was affected through the optimization process. As illustrated in Figure 15, the profile of the on-load cogging torque of Case 2 is similar to the that of the no-load cogging torque. This indicates that the optimization process based on the on-load Back-EMF also reduced the sensitivity of the cogging torque to the increase of the electric load, facilitating the design of the machine controls, since the machine's parameters remained unaltered within a wide range of electric loads (from 0 to $10 \mathrm{~A}$, in this study).

Future studies should focus on testing different optimization methods to reduce the computational effort and include other machine dimensions (e.g., tooth height, tooth tip height, etc.).

\section{ACKNOWLEDGMENTS}

The authors gratefully acknowledge the Brazilian research funding agencies FAPEG (Fundação de Amparo à Pesquisa do Estado de Goiás) and Coordenação de Aperfeiçoamento de Pessoal de Nível Superior - Brasil (CAPES) (Finance Code 001) for their financial support of this work.

\section{REFERENCES}

[1] D. Miyagi, S. Nakazaki, and N. Takahashi, "Optimization of Electromagnetic and Magnetic Shielding Using ON/OFF Method," IEEE Trans. Magn., vol. 46, no. 8, pp. 3153-3156, September 2010.

[2] D. Miyagi, S. Shimose, N. Takahashi, and T. Yamada, "Optimization of Rotor of Actual IPM Motor Using ON/OFF Method,” IEEE Trans. Magn., vol. 47, no. 5, pp. 1262-1265, May 2011.

[3] J. B. Kim, K. Y. Hwang, and B. I. Kwon, "Optimization of Two-Phase In-Wheel IPMSM for Wide Speed Range by Using the Kriging Model Based on Latin Hypercube Sampling," IEEE Trans. Magn., vol. 47, no. 5, pp. 1078-1081, May 2011.

[4] Y. Duan and D. M. Ionel, "A Review of Recent Developments in Electrical Machine Design Optimization Methods with a Permanent-Magnet Synchronous Motor Benchmark Study," IEEE Trans. Ind. Appl., vol. 49, no. 3, pp. 1268-1275, MayJune 2013.

[5] K. Yamazaki and H. Ishigami, "Rotor-Shape Optimization of Interior-Permanent-Magnet Motors to Reduce Harmonic Iron Losses," IEEE Trans. Ind. Electron., vol. 57, no. 1, pp. 61-69, January 2010.

[6] H. C. Liu, I. G. Kim, Y. J. Oh, J. Lee, and S. C. Go, "Design of Permanent Magnet-Assisted Synchronous Reluctance Motor for Maximized Back-EMF and Torque Ripple Reduction,” IEEE Trans. Magn., vol. 53, no. 6, June 2017. 8202604.

[7] P. Ponomarev, I. Petrov, N. Bianchi, and J. Pyrhönen, "Selection of Geometric Design Variables for Fine Numerical Optimizations of Electrical Machines," IEEE Trans. Magn., vol. 51, no. 12, December 2015. 8114808.

[8] T. Sato, K. Watanabe, and H. Igarashi, "Multimaterial Topology Optimization of Electric Machines Based on Normalized Gaussian Network,” IEEE Trans. Magn., vol. 51, no. 3, March 2015. 7202604.

[9] W. Zhao, T. A. Lipo, and B. I. Kwon, "Optimal Design of a Novel Asymmetrical Rotor Structure to Obtain Torque and Efficiency Improvement in Surface Inset PM Motors,” IEEE Trans. Magn., vol. 51, no. 3, March 2015. 8100704.

[10] W. Zhao, F. Zhao, T. A. Lipo, and B. I. Kwon, "Optimal Design of a Novel V-Type Interior Permanent Magnet Motor with Assisted Barriers for the Improvement of Torque Characteristics," IEEE Trans. Magn., vol. 50, no. 11, November 2014. 8104504.

Brazilian Microwave and Optoelectronics Society-SBMO

received 29 Oct 2018; for review 1 Nov 2018; accepted 25 July 2019 
Journal of Microwaves, Optoelectronics and Electromagnetic Applications, Vol. 18, No. 3, September 2019376 DOI: http://dx.doi.org/10.1590/2179-10742019v18i31511

[11] Z. Aza, Z. Q. Zhu, and G. Ombach, “Torque-Speed Performance Analysis of Fractional Slot PM Machines Having Concentrated Windings Using Alternate Methods," in Proc. 6th IET Int. Conf. Power Electron. Mach. Drives (PEMD), Mar. 2012, p. B73.

[12] N. Bianchi and S. Bolognani, "Magnetic Models of Saturated Interior Permanent Magnet Motors Based on Finite Element Analysis," Conf. Rec. 1998 IEEE Ind. Appl. Conf. Thirty-Third IAS Annu. Meet., vol. 1, p. 27-34, 1998.

[13] G. T. Paula, J. R. B. A. Monteiro, B. P. Alvarenga, T. E. P. Almeida, W. C. A. Pereira, and M. P. Santana, "On-Load Back EMF of PMSM Using Maxwell Stress Tensor," IEEE Trans. Magn., vol. 54, no. 7, July 2018. 8104115.

[14] G. T. Paula, Assessment of Surface Mounted Magnet Synchronous Machine's On-Load Back-EMF, Ph.D. thesis, Univ. São Paulo, São Carlos, 2016.

[15] L. H. R. Jesus and L. C. Brito, "Interactive Evolution Strategies for Minimizing Single-Objective Functions," IEEE Latin America Trans., vol. 15, no. 5, pp. 981-987, May 2017.

[16] I. Rechenberg, Cybernetic solution path of an experimental problem, Royal Aircraft Establishment, United Kingdom, 1965.

[17] H. P. Schwefel, Numerical Optimization of Computer Models, John Wiley \& Sons, United Kingdom, 1981.

[18] C. Magele, Evolution Strategies and Optimization, IGTE Graz University of Technology, Austria, 2001.

[19] T. Bäck and H. P. Schwefel, “An overview of evolutionary algorithms for parameter optimization,” Evolutionary Computation, vol. 1, no. 1, pp. 1-23, 1993.

[20] T. Bäck and H. P. Schwefel, "Evolutionary computation: An overview," IEEE International Conference on Evolutionary Computation, pp. 20-29, 1996.

[21] H. P. Schwefel, Evolution and Optimum Seeking, John Wiley \& Sons, New York, 1995.

[22] T. Bäck, H. P. Schwefel and G. Rudolph, "Evolutionary Programming and Evolution Strategies: Similarities and Differences," In Proceedings of the Second Annual Conference on Evolutionary Programming, 1993.

[23] T. Bäck, "Evolutionary Algorithms in Theory and Pratice," Oxford University Press, New York, 1996. 